\title{
Entrepreneurial Prisoners
}

Daniel Johnson

Tn my 44 years, I have lived all over the United States, from New York to in their prison system four times! In all honesty, I am one of those people who have never been arrested while sober. Most of the men I have met in prison, who continually struggle to break the cycle of recidivism, would give their right arms to discover the one thing that would change their lives and keep them out of trouble. I am blessed to know precisely what obstacle I must remain on top of: alcoholism. Therefore, I am gratefully committed to sobriety and recovery.

Too bad I had to spend sixteen years behind bars to finally surrender to reality. I also happen to be one of those people who, while joining up and attending eagerly enough, just do not seem to take or "get it" when it comes to those multitudinous programs that saturate the carceral milieu. I have tried everything. However, I will not cite the various avenues I took to no avail because every one of them is valuable and useful - to a mind/heart that is ripe for transformation. The time must be right.

The intent of this short piece is to share two elements that have come to dominate my consciousness in a profoundly positive and life-changing way. The first is, believe it or not, a program (yeah, I know). The second is the opportunity I have found to build a business that will provide many other prisoners with a change to give something beneficial to society - namely, their artwork and writings.

Here in Texas, I am fortunate to be a part of a rather unique initiative called the Prison Entrepreneurship Program (PEP). Based in Houston, PEP is a 501(c)(3) non-profit organization that was founded in 2004 and recruits this nation's top business, political and academic talent to work with selected current and former prisoners. The stated goal is to create servant-leaders who are dedicated to transformation through education, mentoring and entrepreneurial passion. More than a thousand CEOs, senior executives, venture capitalists, and private investors have sacrificed their time and money to ensure the very best results.

The Texas Department of Criminal Justice does not run this program; it is privately funded and operated. Donations come from corporations ( 15 per cent), individuals ( 35 per cent) and foundations (50 per cent). No government funding is solicited or provided. A large number of donors are themselves graduates of the program who, having established a successful life in the free world, give back heartily. 
There are about 800 graduates from 17 classes, often described as MBA boot camps, each cycle lasting approximately six months. As a member of Class 18, I graduated alongside more than 80 others in December 2012. And what is more, my prison term expired weeks after that and I walked out the door with no parole. But it did not end there. In addition to receiving the education of the in-prison curriculum - hundreds of hours of lectures on creating profitable business plans, understanding financial analysis and budgets, writing résumés, perfecting job-interview techniques, developing speechmaking skills with the help of Toastmasters International, gaining computer skills, handling corporate bookkeeping/accounting, passing weekly exams covering material from the numerous textbooks which are assigned - graduates even receive help following release from prison.

Since its inception, PEP and alumni have demonstrated a less than 5 per cent recidivism rate. Graduates have started more than 100 new businesses. PEP has a professional network in place to ensure that their members have a safe place to live, upon release, and other needs met. The employment rate for our participants is 98 per cent within 60 days of release.

In less than a year, I am to launch a small, independent publishing company that will specialize in handling the artwork and writings of prisoners. I believe creative people behind bars need to be discovered; they have stories to tell and visions to share. Unfortunately, when prisoners produce lasting art and literature, the preponderance of their creations never see the light of day, which only professional publication can grant. I am seeking not only short pieces for compilation but also full-length book manuscripts: novels, autobiographies, memoirs, collections of essays/short stories, biographies about other prisoners and the like while in prison, I would love to share it with the free world.

\section{ABOUT THE AUTHOR}

Daniel Johnson was incarcerated in Texas. He can be contacted johnsondan717@gmail.com, johnsondan68@aol.com. For more information on the Prison Entrepreneurship Program visit www.PEP.org or write to the following address:

PEP

P.O. Box 926274

Houston, Texas 77292-6274

USA 